\title{
Refugees and Sustainable Health Development in Iran
}

\author{
Mohammad Mehdi Kiani, PhD Candidate ${ }^{1,2}$; Khatere Khanjankhani, PhD Candidate'; Afsaneh Takbiri, PhD ${ }^{1}$; Amirhossein Takian, MD, \\ $\mathrm{PhD}^{1,2,3^{*}}$ \\ 'Department of Health Management and Economics, School of Public Health,Tehran University of Medical Sciences (TUMS), Tehran, Iran \\ ${ }^{2}$ Health Equity Research Center (HERC), Tehran University of Medical Sciences (TUMS), Tehran, Iran \\ ${ }^{3}$ Department of Global Health and Public Policy, School of Public Health, Tehran University of Medical Sciences, Tehran, Iran
}

\begin{abstract}
Background: Refugees' access to quality healthcare services might be compromised, which can in turn hinder universal health coverage (UHC), and achieving Sustainable Development Goal (SDG), ultimately.

Objective: This article aims to illustrate the status of refugees' access to healthcare and main initiatives to improve their health status in Iran.

Methods: This is a mixed-method study with two consecutive phases: qualitative and quantitative. In the qualitative phase, through a review of documents and semi-structured interviews with 40 purposively-selected healthcare providers, the right of refugees to access healthcare services in the Iranian health system was examined. In the quantitative phase, data on refugees' insurance coverage and their utilization from community-based rehabilitation (CBR) projects were collected and analyzed.

Results: There are international and upstream policies, laws and practical projects that support refugees' health in Iran. Refugees and immigrants have free access to most healthcare services provided in the PHC network in Iran. They can also access curative and rehabilitation services, the costs of which depend on their health insurance status. In 2015, the government allowed the inclusion of all registered refugees in the Universal Public Health Insurance (UPHI) scheme. Moreover, the mean number of disabled refugees using CBR services was 786 ( \pm 389.7$)$. The mean number of refugees covered by the UPHI scheme was 112,000 $( \pm 30404.9)$.

Conclusion: The United Nations' SDGs ask to strive for peace and reducing inequity. Along its pathway towards UHC, despite limited resources received from the international society, the government of Iran has taken some fundamental steps to serve refugees similar to citizens of Iran. Although the initiative looks promising, more is still required to bring NGOs on board and fulfill the vision of leaving no one behind.

Keywords: Iran, Refugees, Sustainable health development, Universal health coverage

Cite this article as: Kiani MM, Khanjankhani K, Takbiri A, Takian A. Refugees and sustainable health development in Iran. Arch Iran Med. 2021;24(1):27-34. doi: 10.34172/aim.2021.05.
\end{abstract}

Received: February 13, 2020, Accepted: October 4, 2020, ePublished: January 1, 2021

\section{Introduction}

Globally, about 214 million people move internationally, while approximately three-quarters of a billion people migrate within their own country, both of which pose considerable challenges to health policy making. ${ }^{1-3}$ As a consequence of war, torture, violations, and disparities in race, religion, nationality, ethnicity, and political freedom, the global number of refugees, migrants, asylum seekers and displaced people has historically reached the highest ever. ${ }^{4}$ According to the United Nations High Commissioner for Refugees (UNHCR), 70.8 million individuals were forced to displace by the end of 2019 worldwide. ${ }^{5}$ This is an increase of 2.9 million people over the previous year, and the world's forcibly displaced population remained at a record high, including: 25.4 million refugees—the highest ever seen; 40 million internally displaced people; and 3.1 million asylum-seekers. Fifty-three percent of refugees come from three countries (Somalia 1, Afghanistan 2.7, Syria 4.2 million). Turkey is the top host country by accommodating 2.5 million refugees. ${ }^{2}$ More than a million refugees and migrants arrived in the European Union in 2015. ${ }^{6}$ The recent wars in Syria, Iraq and other countries have caused large-scale displacement and refugees who are seeking to migrate to safe countries to live. ${ }^{7}$

Cross-border migrants have heterogeneous life experiences and they may have experienced discrimination and marginality before, during, or after travel. ${ }^{8}$ As a result, migrants face higher risk of infectious diseases, non-communicable diseases (NCDs) and mental health problems. ${ }^{6}$ The greater diversity of refugee population has brought new challenges to the national health care systems, ${ }^{9}$ especially for countries that host a large numbers of them. ${ }^{10}$ Refugees and asylum seekers are vulnerable groups with significant and complex health needs. ${ }^{11}$

Migration is considered a social, political and health challenge, in terms of providing access to high quality health services in order to achieve Sustainable Development Goals (SDGs), and particularly the concept of universal health coverage (UHC). ${ }^{12}$ SDG 3 aims to 'ensure healthy lives and promote well-being for all at all 
ages', including that of migrants, while a number of other SDGs incorporate elements related to health outcomes and migration. Key development issues such as health, education, labor, gender, and urbanization are among the elements that may affect refugees' populations. Improving migrants and all vulnerable people's health depends on equity, as countries work towards achieving SDGs, particularly those related to poverty, inequality, hunger and food insecurity, employment and peace. ${ }^{6}$

For nearly four decades, the Islamic Republic of Iran has provided asylum for refugees and is currently the host to millions of refugee. ${ }^{13}$ Iran hosts 979,410 documented (registered and issued refugee identity cards [Amayesh]) Afghan refugees (1 May 2019). ${ }^{5}$ There are also an estimated 1.5 to 2 million undocumented Afghans in Iran. ${ }^{14}$ In addition, at least 620000 Afghans who hold Afghan passports and Iranian visas also live in Iran. ${ }^{15}$ Most refugees reside in urban settings, with only less than 3\% living in 20 settlements by the UNHCR , enjoying comprehensive regularization plan. ${ }^{16,17}$ Further, about 32000 Iraqi nationals live as refugee in Iran. ${ }^{18}$ Iran's government has been implementing many initiatives to improve refugees' access to health care in the country, mostly using domestic resources. Recently, in response to refugees' health needs and with the implementation of health transformation plan (HTP), the Iran's pathway toward universal health coverage, new policies have been launched to expand social insurance and improve access and quality of healthcare services for refugees in Iran. ${ }^{19}$ This article aims to illustrate the status of refugees and immigrants' access to healthcare and main initiatives to improve their health in Iran.

\section{Materials and Methods}

This is a mixed-method study with two consecutive phases.

\section{Qualitative Study Phase}

First, using targeted sampling, we conducted content analysis of selected key documents (See Table 1). The inclusion criteria were the communication of the document by the Supreme Leader, Constitution Law, approval by the Islamic Consultative Assembly of Iran, approval by the Ministry of Health and Medical Education and international nature. Regarding international treaties, those that Iran had accepted were selected. Based on these criteria, seven documents were selected and content analyzed.

The aim of this phase was to investigate the international as well as upstream national policies and laws that support refugee's health and identified healthcare services provided for refugees in Iran.

The results of literature review helped us to prepare an interview guide which we used to conduct 40 semistructured interviews with purposefully identified key informants, i.e. healthcare providers from both PHC and rehabilitation service, aiming to investigate the facilitators of and barriers to refugees' access to healthcare services in Iran.

The interviews were performed between May and August 2017 and took place at participants' workplaces. The interviewees were initially informed of the study objectives, data collection, interview recordings and their role in the study, while we ensured them about data confidentiality. Depending on their willingness, the interviewees gave their written or verbal consent. The interviews were digitally recorded and transcribed verbatim. Except for two cases, where the interviewees did not allow recording, all interviews were transcribed by the researchers. The mean time of the interviews was around 30 minutes.

We used the thematic analysis approach to data analysis. First, we became familiar with the scope and variety of the transcripts, and then, one researcher (AT2) began to identify the key concepts and issues to set the initial thematic framework. The identified constructs and themes were then compared with some relevant theories and experiences to identify the concepts and contradictions, aiming to draw similar patterns and relationships from the findings.

\section{Quantitative Study Phase}

Second, we obtained the existing descriptive statistics about refugees who were insured by the Universal Public Health Insurance (UPHI) scheme, as well as the number of refugees with disability who were covered under the community-based rehabilitation (CBR) projects (2013-2017). The source of data was the Ministry of Health and Medical Education (MoHME), Iran's Health Insurance Organization (IHIO) and the National Welfare Organization (NWO). Two quality checklists were used

Table 1. Selected Documents About Refugee's Rules in Iran

\begin{tabular}{ll}
\hline Number & Selected Documents \\
\hline 1 & The 1951 convention relating to the status of refugees and its 1967 protocol \\
2 & Mega policies for health by Supreme Leader \\
3 & Universal Right for Social Security in Iran \\
\hline 5 & The 5th Five-Year National Development Plan (2010-2015) \\
\hline 6 & The 6th Five-Year National Development Plan (2016-2021) \\
\hline & Improving Maternal Health in Afghanistan and for Afghan Refugees in Iran through South-South Cooperation \\
\hline
\end{tabular}


to collect quantitative data. The SPSS software version 21 was used to conduct statistical analysis.

Finally, both sources of data were merged to describe the current status of healthcare service provision for refugees in Iran.

\section{Results}

We present our findings in two parts: qualitative and quantitative.

\section{Qualitative results}

We classified our qualitative findings in two main categories: Iran's commitment to providing healthcare services to refugees, and refugees' access to healthcare services (PHC, hospital healthcare and CBR).

\section{Iran's Commitment to Provide the Refugees' Healthcare Services}

Table 2 summarizes some international and upstream policies, laws and practical projects that demonstrate Iran's commitment to refugees' health needs in Iran.

Iran has been hosting millions of documented and undocumented refugees in the course of the last four decades. In line with humanitarian action, Iran has prioritized refugees' health by moving beyond its duties and responsibilities set in the 1951 Convention for serving refugees. For instance, despite some reservations about some articles of the convention, Iran has taken effective steps in order to promote the quality of life for millions of Afghan refugees, documented and mostly undocumented alike. The government of Iran grants the refugees' population access to medical services, education for students, literacy classes for out of-school children and the labor market.

Following mega policies for health, decreed by the Supreme Leader in May 2015, the government of Iran has been improving access to public education for all children of undocumented refugees to enroll in Iranian schools, and have equal access as Iranians to healthcare centers for immunization, screening, and all other services. Later, the Bureau for Aliens and Foreign Immigrants' Affairs (BAFIA) at the ministry of interior decided that all undocumented Afghans whose children are enrolled in school will be safe from deportation.

Article 29 of the constitution of Iran recognizes a universal right of access to health and medical treatments through social insurance and other means. Health insurance coverage of foreign residents living in the country has been noted in Article 28 and Article 70, the 5 ${ }^{\text {th }}$ (2010-2015) and the $6^{\text {th }}(2016-2021)$ Five-Year National Development Plans of Iran, respectively.

In response to refugees' health care needs, Iran's government has expanded its universal health insurance scheme to cover all registered refugees in the country. In 2015, the government allowed the inclusion of all registered refugees in the UPHI scheme. A four-phase (2015-2018) joint program by IHIO, MOHME, UNHCR Iran and BAFIA was defined to provide refugees with universal health insurance coverage within HTP, similar to citizens of Iran.

At the international level, in the format of fostering southsouth collaboration, since 2016, Iran has been leading in a global project aiming at contributing to improvement of maternal health and reducing maternal mortality ratio

Table 2. International and Upstream Policies, Laws and Practical Projects Supporting Refugees' Health in Iran

\begin{tabular}{|c|c|}
\hline Document & Description \\
\hline $\begin{array}{l}\text { The } 1951 \text { convention related to the status of } \\
\text { refugees and its } 1967 \text { protocol }\end{array}$ & $\begin{array}{l}\text { The Iranian government approved the } 1951 \text { Refugee Convention and its protocol (1967) on July 28, } 1976 \\
\text { with reservations on articles } 17 \text { (wage-earning employment), } 23 \text { (public relief), } 24 \text { (labor legislation and } \\
\text { social security) and } 26 \text { (freedom of movement). }{ }^{20}\end{array}$ \\
\hline Mega policies for health by Supreme Leader & $\begin{array}{l}\text { All children (including undocumented children) can access public education (May 2015) that led the } \\
\text { government to begin gradual registration of undocumented children, of whom some } 48000 \text { were enrolled } \\
\text { in schools. }{ }^{21}\end{array}$ \\
\hline $\begin{array}{l}\text { Universal Right for Social Security in Iran: } \\
\text { Article } 29 \text { of the constitutional law }\end{array}$ & $\begin{array}{l}\text { It is a universal right to enjoy social security and have benefits with respect to retirement, unemployment, } \\
\text { old age, workers' compensation, lack of guardianship and destitution. In case of accidents and } \\
\text { emergencies, everyone has the right to health and medical treatments through insurance or other means. } \\
\text { In accordance with the law, the government is obliged to use the proceeds from the national income and } \\
\text { public contributions to provide the above-mentioned services and financial support for each and every } \\
\text { one of citizens. }{ }^{22}\end{array}$ \\
\hline $\begin{array}{l}\text { The 5th Five-Year National Development Plan } \\
\text { (2010-2015), Article 28, part D }\end{array}$ & $\begin{array}{l}\text { All foreign nationals residing in the country are obliged to have insurance to cover possible accidents and } \\
\text { illnesses during their stay in Iran. The Central Insurance Organization of Iran is responsible for determining } \\
\text { the tariff. } .^{23}\end{array}$ \\
\hline $\begin{array}{l}\text { The 6th Five-Year National Development Plan } \\
\text { (2016-2021): Article 70, number } 5\end{array}$ & $\begin{array}{l}\text { Health insurance coverage is required for foreign residents living in the country, including group refugees } \\
\text { who are recognized by the Ministry of Interior. }{ }^{24}\end{array}$ \\
\hline $\begin{array}{l}\text { Improving Maternal Health in Afghanistan and } \\
\text { for Afghan Refugees in Iran through South- } \\
\text { South Cooperation }\end{array}$ & $\begin{array}{l}\text { The overall objective of this project was to improve maternal health in Afghanistan and for Afghan refugees } \\
\text { living in Iran. }\end{array}$ \\
\hline Health Transformation Plan (HTP) & In 2015, the government allowed the inclusion of all registered refugees in the UPHI scheme. \\
\hline
\end{tabular}


in Afghanistan. The MoHME negotiated and secured a foreign fund and liaised with the United Nations' Population Fund (UNFPA) to reach three outputs: first, an Iranian-Afghan academic collaboration was established to build the capacity of the midwifery department at Kabul Medical University. Second, establishment of an Afghanfriendly maternity ward at a hospital in south Tehran and finally, training 10 Master of Science (MSc) and 50 Bachelor (BSc) Afghan women in Iran using the Afghan midwifery curriculum. The graduates of the course will return to Afghanistan to improve practice towards better maternal health and reduction of maternal mortality ratioin Afghanistan.

\section{The Right of Refugees' Access to Healthcare in Iran}

Here, we report on refugees' access to PHC, curative services and rehabilitation services in Iran.

\section{Refugees' Access to PHC Services}

Similar to Iranian citizens, all migrants and refugees (including undocumented immigrants) can access freeof-charge PHC. Free PHC services include vaccinations, antenatal care, maternal and child health, family planning, health promotion activities, nutrition and psychology counseling, antiretroviral therapy for HIV/AIDS, treatment for tuberculosis, etc.

Some PHC service providers pointed to Iran's commitment to providing necessary services to all refugees in need, irrespective of their migration status, which was due to the external effects of health and disease.

"Well, if we want to keep Iranians healthy, we have to do all these services for Afghans, as well. For example, if vaccination is not given to Afghan children and they become ill, they may infect all the residents of a village. So, such services should be provided to Afghans in a completely similar way [to Iranians]" (P8).

"We can't look at the status of a person's residence, which means there's no need to do that at all. [For example] when a patient has tuberculosis, it is not possible to discuss whether his or her residence is legal or illegal. Instead, he or she should be treated. Because [his or her health status] endangers others... And we can't ignore him owing to his or her residence is not legal. Because [his or her illness] can infect others. There is no difference between communicable or non-communicable diseases (P4).

Some interviewees stated that Iranians and non-Iranians do not have to pay for free services. In the case of some selected expensive services, a nominal co-payment fee would be payable, if the patient is covered by an insurance scheme.

\section{Refugees' Pathway to Access Curative Services in Iran}

Regarding access to health services, the respondents reported that all Afghan immigrant groups have access to health services, and that the Iranian health system has not imposed a restriction to serve immigrants. Nevertheless, the cost of services varies depending on their insurance coverage.

"We are not banned from serving anyone, but the only difference is the cost. For uninsured refugees, the cost is the same as for an uninsured Iranian patient" (P40).

According to one respondent, the unconditional acceptance of immigrants, especially in the case of emergency patients, is due to ethical and legal considerations.

"We do not differentiate between Iranians and Afghans. This means that everyone coming to the clinic or emergency room, outpatient or emergency, with or without identity, with or without ID, Iranian or Afghan, is no different for us. When a patient is in an emergency, the question is not whether you have money. If his or her answer is no, can we not accept him or her? Its legal aspects are on one side and some moral aspects are on the other side. So far, we have not returned the patient due to financial issues. That's why patients come to us without any problems" (P26).

Table 3 shows the refugees' pathway to access curative services in Iran. These services contain emergency, outpatient and inpatient services.

Refugees' Access to Community-Based Rehabilitation Services Similar to Iranian citizens, refugees can access all rehabilitation services provided in public or private centers. Moreover, refugees with disabilities can access CBR services including: required surgery to reduce disability, medical referral and treatment (e.g. cost of doctor visits, medications, testing and para-clinical services), referrals to rehabilitation centers to receive physical therapy, occupational therapy, speech therapy, audiology, optometry, psychology and rehabilitation counseling and provision of assistive technologies. CBR is a joint initiative among the State Welfare Organization (planning, implementing and monitoring of the projects), BAFIA (coordinating and providing information on disabled refugees) and the Office of the UNHCR in Iran

Table 3. Refugees' Pathway to Access Curative Services in Iran

\begin{tabular}{lll}
\hline Type of Services & Refugees without Insurance & Refugees with Insurance \\
\hline Emergency services & Admission in hospitals and receiving care, paying total cost of care & Admission in hospitals and receiving care, paying only copayment \\
Inpatient services & Admission in hospitals and receiving care, paying total cost of care & Admission in hospitals and receiving care, paying only copayment \\
Outpatient services & Admission in hospitals and receiving care, paying total cost of care & Admission in hospitals and receiving care, paying only copayment \\
\hline
\end{tabular}


(partial financial supporting and coordination).

One interviewee explained the right of access to CBR services.

"Community-based rehabilitation projects have been running for refugees for 10 years. We served the Iraqis for one year. But because the Afghan language is Persian and easy to communicate, as well as the problems of the Arabic language and the inability to communicate and the small number of Iraqis, the Iraqis were excluded from receiving services in the following years. We have been providing services to Afghans for almost ten years (except for one year), and this is a group of people who must have a residence card" (P31).

\section{Quantitative results}

\section{Utilizations of CBR Services by Disabled Refugees}

During the 5 years of the CBR project for refugees, an average of $786 \pm 389.7$ refugees benefited from the service each year. Since the project began in 2013, the number of provinces involved and the number of asylum seekers using CBR services have been increasing (Table 4).

Universal Public Health Insurance (UPHI) Coverage for Refugees in Iran

Since 2014, Iran has begun a set of policy reforms towards universal health coverage (UHC), so-called the HTP, and population coverage has increased from 68\% in 2007 to $92 \%$ in 2015 (Figure 1).

Social Security Organization (SSO)/ Iran Health Insurance Organization(IHIO)

During the four phases of the UPHI project for refugees, an average of $112000 \pm 30404.9$ refugees were covered by insurance each year. Most of the insured were also vulnerable refugees (Table 5).

\section{Discussion}

This article reported a summary of initiatives to enhance refugee's access to healthcare services in Iran. As refugees might be prone to disabling conditions such as vulnerability, homelessness and poverty, they might develop higher degrees of stress and mental problems, which can seriously affect their health conditions ultimately. ${ }^{25}$

Various upstream policies prioritize and pay good attention to refugees' health and education in Iran. ${ }^{26}$ One study on the health and dignity of Palestinian refugees in Jordan, Lebanon, Syria and the Gaza strip showed the necessity of developing the applicable international laws and the UN General Assembly resolutions to protect the refugees' dignity. ${ }^{27}$ The Australian law requests refugees' health information to be kept confidential. ${ }^{28}$ Another study showed that host governments should have a moral obligation to the health needs of migrants and refugees. ${ }^{29}$ Others have called for a strong and coordinated support at the global, national and subnational levels to ensure that refugees remain a priority in societal plans. ${ }^{30}$ According to the Asylum Law in Germany, newly arrived refugees must receive a health insurance card that provides them with screening services for some communicable diseases. ${ }^{31}$ Another study illustrated significant problems among undocumented migrants, asylum seekers and refugees as they might not be fully entitled to receive primary and secondary care through different parts of national health systems across 28 countries of the European Union. ${ }^{32}$ The refugees' right to healthcare services is rooted in the law because it is firstly a human right and is secondly crucial to maintain refugees' health and improve the entire community's health. Although refugees' rights to healthcare have been highlighted in Iran's law, more awareness attempts are needed to enhance refugees' knowledge about their rights and obligations to enable them to benefit from their rights.

Since HTP began in 2014, refugees in Iran are entitled to universal public health coverage to enjoy healthcare services (prevention, curative services and rehabilitation) at all levels. Statistics show that the trend of refugees' access to community-based rehabilitation services has increased from 2013 to 2017. CBR services for refugees are provided in Iran through partnerships between the State Welfare Organization of Iran, Bureau for Aliens and Foreign Immigrants Affairs and UNHCR. ${ }^{25}$ A research on 120 refugees in Denver, USA revealed that $41 \%$ of respondents without health insurance, while 31\% expressed their health status as poor and unfair. ${ }^{33}$ Another study showed that the burden of health conditions such as malnutrition, anemia, hepatitis A and B, NCDs and lack of access to medicine were significant among refugees. ${ }^{34,35}$ In Germany, although access to all health services is not granted across all states; the Hamburg state, for instance, has unrestricted access to healthcare for refugees with health insurance cards, despite some barriers. ${ }^{36}$ Another study in the United States showed that $46.5 \%$ refugees with chronic disease were uninsured. ${ }^{37}$ One study on Syrian refugees in Jordan highlighted lack of insurance coverage as one of the barriers to accessing cancer care. ${ }^{38}$ Another study on Syrian refugee children in Jordan showed that households seek $54.6 \%$ of the services from the public sector, $36.5 \%$ from the private sector and $8.9 \%$ from charities. ${ }^{39} \mathrm{~A}$

Table 4. Refugees with Disability Under CBR Projects

\begin{tabular}{lcccccc}
\hline Year & $\mathbf{2 0 1 3}$ & $\mathbf{2 0 1 4}$ & $\mathbf{2 0 1 5}$ & $\mathbf{2 0 1 6}$ & $\mathbf{2 0 1 7}$ & Mean \pm Standard Deviation \\
\hline Number of provinces participating in CBR project & 5 & 3 & 4 & 11 & 12 & $7 \pm 4.1$ \\
Number of refugees with disability using CBR services & 550 & 300 & 720 & 1160 & 1200 & $786 \pm 389.7$ \\
\hline
\end{tabular}




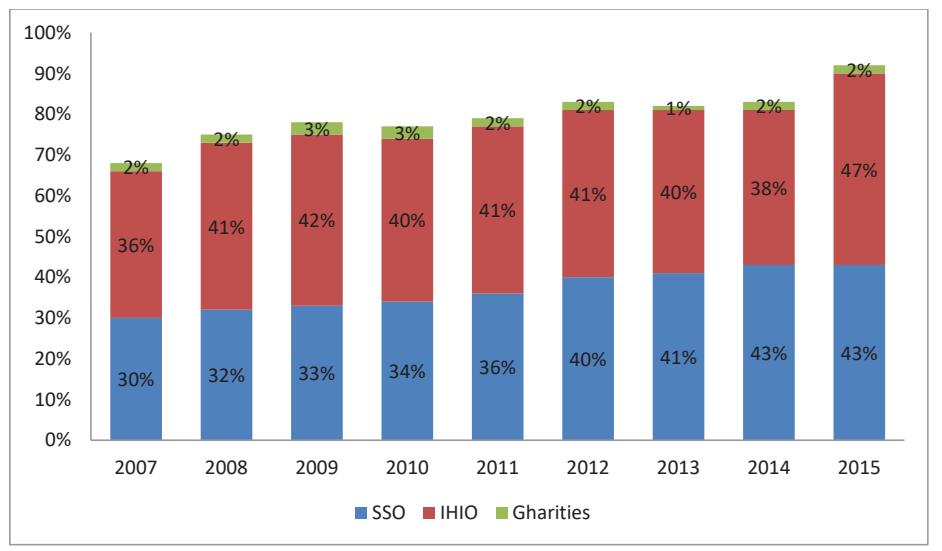

Figure 1. Trend of Iranian Insurance Coverage from 2007 to 2015.

complementary study by the same researchers among 1550 non-camp refugees revealed that almost half of the services were sought from the public sector $(51.5 \%), 38.7 \%$ from the private sector and $9.8 \%$ from non-governmental organizations (NGOs) and charities..$^{40}$ A study in Lebanon found that despite availability of international assistance for refugees, more coordination is still necessary at the Ministry of Health level. ${ }^{41}$ Another study illustrated that language barriers among Syrian refugees who do not live in camps have caused inadequate access to healthcare. ${ }^{42}$ The government of Jordan and the United Nations are currently implementing CBR programs within refugee camps. ${ }^{43}$ Several case studies point out the importance of simultaneous provision of health insurance coverage as well as need-based services to improve refugees' health. Three dimensions need to be considered to achieve UHC for refugees: provision of insurance coverage to all refugees, preparing a need-based service package for refugees, and effective mechanisms for financial protection and avoiding catastrophic costs due to healthcare.

As in the case of Iran, NGOs and charity organizations play an important role in supporting refugees' health. These include, but are not limited to Mahak Charity (helping children with cancer through a hospital in the north of Tehran), Behnam Daheshpour Charity (helping patients in need of cancer care) and Zanjireh Omid (treating underprivileged children suffering from cardiac, orthopedic and reconstructive diseases). ${ }^{16}$ One study showed that $8.9 \%$ of Syrian refugees referred to charity centers for child care services, ${ }^{44}$ whereas another study in Australia showed that $23 \%$ of respondents expressed difficulties in having access to charity services. ${ }^{45}$ The results of a study on welfare and posttraumatic growth among 250 Syrian refugees in Jordan showed that 74.6\% of participants received services through NGOs. ${ }^{46}$ Another study on the use of NCD-related health services among Syrian refugees in Jordan showed that $53.9 \%$ of services were provided by the public sector, $29.6 \%$ by the private sector and $16.6 \%$ by charities and NGOs. ${ }^{40}$ In Lebanon, many patients continue to be strongly in need of healthcare support, which might be only resolved through collaboration between governmental and NGOs. ${ }^{47}$ The capacity of civil society, i.e. local communities, charities and NGOs in improving the health and well-being of refugees needs more elaboration and concrete establishment within many countries that host refugees.

In conclusion, refugees have been facing inequalities in their healthcare status anywhere. Refugees' health can be a big challenge to universal health coverage, across high and middle-income countries alike. The United Nations' vision 2030 of SDGs asks to strive for peace and reducing inequity. Along its HTP pathway towards UHC, despite limited resources received from the international society, the government of Iran has taken a few fundamental steps to bring in refugees similar to citizens of Iran. Although the initiative looks promising, more is still required to bring NGOs on board and fulfill the vision of leaving no one behind.

Table 5. Number of Refugees Insured by UPHI

\begin{tabular}{|c|c|c|c|c|c|c|c|c|c|}
\hline \multirow[t]{2}{*}{ Phase } & \multicolumn{2}{|c|}{$\begin{array}{c}\text { Refugees with } \\
\text { Special Diseases }\end{array}$} & \multicolumn{2}{|c|}{$\begin{array}{c}\text { Vulnerable } \\
\text { Refugees }\end{array}$} & \multicolumn{2}{|c|}{$\begin{array}{l}\text { Other Refugees } \\
\text { (Non-vulnerable) }\end{array}$} & \multicolumn{2}{|c|}{ Total } & \multirow{2}{*}{$\begin{array}{c}\text { Mean } \pm \text { Standard } \\
\text { Deviation }\end{array}$} \\
\hline & $\mathbf{n}$ & $\%$ & $\mathbf{n}$ & $\%$ & $\mathbf{n}$ & $\%$ & n & $\%$ & \\
\hline UPHI Phase 1: (1 October 2015-2028 March 2016) & 1007 & 1.1 & 59707 & 69.2 & 25513 & 29.5 & 86227 & 100 & \multirow{4}{*}{$112000 \pm 30404.9$} \\
\hline UPHI Phase 2: (28 September 2016-2024 February 2016) & 1128 & 0.7 & 116687 & 80.09 & 27866 & 19.1 & 145681 & 100 & \\
\hline UPHI Phase 3: (25 February 2016-2024 February 2017) & 1006 & 0.7 & 112735 & 87.01 & 15820 & 12.2 & 129561 & 100 & \\
\hline UPHI Phase 4: (25 February 2017-2024 February 2018) & 1057 & 1.2 & 72358 & 83.9 & 12771 & 14.8 & 86186 & 100 & \\
\hline
\end{tabular}




\section{Authors' Contribution}

AHT conceived the study, obtained funding, designed methodology and supervised the entire research. MMK, KK and AFT wrote the manuscript and contributed to its revision. AFT conducted qualitative data collection and analysis. All authors contributed to the intellectual development and approved the final manuscript. AHT is guarantor.

\section{Conflict of Interest Disclosures}

Authors have no conflict of interest to declare.

\section{Ethical Statement}

An ethics approval was obtained for this study from the research ethics committee of Tehran University of Medical Sciences (Approval Number: IR.TUMS.REC.1394.1776).

\section{Acknowledgements}

Authors would like to thank all participants for their collaborations in data collection and Tehran University of Medical Sciences for funding the qualitative part of the study.

\section{References}

1. Zimmerman C, Kiss L, Hossain M. Migration and health: a framework for 21 st century policy-making. PLoS Med. 2011;8(5):e1001034. doi: 10.1371/journal.pmed.1001034

2. Klugman J. Human development report 2009. Overcoming barriers: Human mobility and development. UN Development Programme (UNDP); 2009. Available from: https://www. refworld.org/docid/4ac9d10d2.html.

3. Permanent Forum on Indigenous Issues, United Nations. State of the world's indigenous peoples. United Nations Publications; 2009.

4. Renzaho A, Dhingra M. Addressing the needs of Syrian and Iraqi refugees in the Nepean Blue Mountains region: A formative assessment of health and community service's needs; 2016.

5. The UN refugee agency. Fact sheet of Iran. 2019. Available from: https://reporting.unhcr.org/sites/default/files/UNHCR\%20 Iran\%20Fact\%20Sheet\%20-\%20October\%202019.pdf.

6. Tulloch O, Machingura F, Melamed C. Health, Migration and the 2030 Agenda for Sustainable Development. England: Overseas Development Institute organization; 2016.

7. Home Europe Situation. Available from: https://www.unhcr. org/tr/en/europe-situation.

8. Hunter-Adams J, Rother HA. A Qualitative study of language barriers between South African health care providers and cross-border migrants. BMC Health Serv Res. 2017;17:9. doi: 10.1186/s12913-017-2042-5

9. Dias SF, Severo M, Barros H. Determinants of health care utilization by immigrants in Portugal. BMC Health Serv Res. 2008;8:20. doi: 10.1186/1472-6963-8-207

10. Hunter P. The refugee crisis challenges national health care systems: countries accepting large numbers of refugees are struggling to meet their health care needs, which range from infectious to chronic diseases to mental illnesses. EMBO Rep. 2016;17(4):492-5. doi: 10.15252/embr.201642171

11. Robertshaw SD L, L-Jones L. Challenges and facilitators for health professionals providing primary healthcare for refugees and asylum seekers in high-income countries: a systematic review and thematic synthesis of qualitative research. BMJ Open. 2017;4(8):e015981. doi: 10.1136/ bmjopen-2017-015981

12. De Vito E, de Waure C, Specchia ML, Parente P, Azzolini E, Frisicale EM, et al. Are undocumented migrants' entitlements and barriers to healthcare a public health challenge for the European Union? Public Health Rev. 2016;37(1):13. doi: 10.1186/s40985-016-0026-3

13. Health of refugees and migrants, Situation analysis and practices in addressing the health needs of refugees and migrants: Examples of public health interventions and practices. WHO Eastern Mediterranean Region; 2018.

14. Garrote-Sanchez D. International Labor Mobility of Nationals: Experience and evidence for Afghanistan at macro level. World Bank; 2017.

15. Takbiri A, Takian A, Foroushani AR, Jaafaripooyan E. The challenges of providing primary health care to Afghan immigrants in Tehran: a key global human right issue. Int J Hum Rights Healthc. 2020;13(3):259-73. doi: 10.1108/ IJHRH-06-2019-0042.

16. Matlin SA, Depoux A, Schütte S, Flahault A, Saso L. Migrants' and refugees' health: towards an agenda of solutions. Public Health Rev. 2018;39:27. doi: 10.1186/s40985-018-0104-9.

17. Global Report 2016. United Nations High Commission for Refugees (UNHCR); 2016. Available from: https://reporting. unhcr.org/sites/default/files/gr2016/pdf/Book_GR_2016_ ENGLISH_complete.pdf

18. Refugees \& Health 2018. Available from: https://watson. brown.edu/costsofwar/costs/human/refugees.

19. Doshmangir L, Bazyar M, Majdzadeh R, Takian A. So near, so far: four decades of health policy reforms in Iran, achievements and challenges. Arch Iran Med. 2019;22(10):592-605.

20. Jadali S. Islamic Republic of Iran and the Issue of Refugees 2010. Available from: http://www.iranreview.org/content/ Documents/Islamic_Republic_of_Iran_and_the_Issue_of_ Refugees.htm.

21. The 6th Five-Year Development Plan (2016-21): Article 70, number 5. Available from: https://policy.asiapacificenergy.org/ node/3671.

22. Papan-Matin F. The Constitution of the Islamic Republic of Iran (1989 Edition). Iranian Studies. 2014;47(1):159-200.

23. The 5th Five-Year Development Plan (2011-15): Article 28 pD. Available from: https://rc.majlis.ir/fa/law/show/790196

24. Wong WCW, Cheung S, Miu HYH, Chen J, Loper KA, Holroyd E. Mental health of African asylum-seekers and refugees in Hong Kong: using the social determinants of health framework. BMC Public Health. 2017;17(1):153. doi: 10.1186/s12889016-3953-5

25. Giacco D, Laxhman N, Priebe S, editors. Prevalence of and risk factors for mental disorders in refugees. Semin Cell Dev Biol. 2018;77:144-152. doi: 10.1016/j.semcdb.2017.11.030

26. Bempong NE, Sheath D, Seybold J, Flahault A, Depoux A, Saso L. Critical reflections, challenges and solutions for migrant and refugee health: 2nd M8 Alliance Expert Meeting. Public Health Rev. 2019;40:3. doi: 10.1186/s40985-019-0113-3.

27. Kitamura A, Jimba M, McCahey J, Paolucci G, Shah S, Hababeh $M$, et al. Health and dignity of Palestine refugees at stake: a need for international response to sustain crucial life services at UNRWA. Lancet. 2018;392(10165):2736-44. doi: 10.1016/S0140-6736(18)32621-7

28. Kenyon G. Australian law could silence critics of refugee health. Lancet Respir Med. 2016;4(3):178. doi: 10.1016/ s2213-2600(16)00018-7

29. Wong WCW, Cheng S, Holroyd E, Chen J, Loper KA, Tran L, et al. A lost tribe in the city: health status and needs of African asylum seekers and refugees in Hong Kong. Int J Equity Health. 2016;15(1):158. doi: 10.1186/s12939-016-0451-4

30. Spiegel PB, Hering H, Paik E, Schilperoord M. Conflictaffected displaced persons need to benefit more from HIV and malaria national strategic plans and Global Fund grants. Confl Health. 2010;4(1):2.

31. Borgschulte H, Bunte A, Neuhann F, Weber L, Wiesmüller G. Health care of refugees in 2015-Evaluation of an ambulance for refugees in a Cologne emergency accommodation (Cologne Model). Gesundheitswesen. 2016;78(12):808-13. doi: 10.1055/s-0042-121251

32. O'Donnell C, Burns N, Dowrick C, Lionis C, MacFarlane A, Team R. Health-care access for migrants in Europe. Lancet. 
2013;382(393):61666-9. doi:10.1016/S0140-6736(13)616669.

33. Elwell D, Junker S, Sillau S, Aagaard E. Refugees in Denver and their perceptions of their health and health care. J Health Care Poor Underserved. 2014;25(1):128-41. doi: 10.1353/ hpu.2014.0032

34. Norredam M, Mygind A, Krasnik A. Access to health care for asylum seekers in the European Union. A comparative study. Lakartidningen. 2006;103(17):1317-9. doi: 10.1093/eurpub/ cki191

35. Gornall J. Healthcare for Syrian refugees. BMJ. 2015; 351:h4150. doi: 10.1136/bmj.h4150

36. Sothmann P, auf der Günne Schmedt N, Addo M, Lohse A, Schmiedel S. Medical care for asylum seekers and refugees at the University Medical Center Hamburg-Eppendorf--A case series. Dtsch Med Wochenschr. 2016;141(1):34-7. doi: 10.1055/s-0041-108775

37. Yun K, Fuentes-Afflick E, Desai MM. Prevalence of chronic disease and insurance coverage among refugees in the United States. J Immigr Minor Health. 2012;14(6):933-40. doi:10.1007/s10903-012-9618-2

38. Al Qadire M, Al-Shdayfat N. Cancer awareness and barriers to seeking medical help among Syrian refugees in Jordan: a baseline study. J Cancer Educ. 2019;34(1):19-25. doi: 10.1007/s13187-017-1260-1.

39. Doocy S, Lyles E, Akhu-Zaheya L, Burton A, Burnham G. Health service access and utilization among Syrian refugees in Jordan. Int J Equity Health. 2016;15(1):108. doi:10.1186/ s12939-016-0399-4.

40. Doocy S, Lyles E, Akhu-Zaheya L, Oweis A, Al Ward N,
Burton A. Health service utilization among Syrian refugees with chronic health conditions in Jordan. PLoS One. 2016;11(4):e0150088. doi: 10.1371/journal.pone.0150088.

41. Blanchet K, Fouad FM, Pherali T. Syrian refugees in Lebanon: the search for universal health coverage. Confl Health. 2016;10(1):12. doi: 10.1186/s13031-016-0079-4.

42. Kaya E, Karadag Caman O, Kilic C, Uner S. Refugees' access to and utilization of health services: challenges and solutions in Turkey. Eur J Pub Health. 2018;28(suppl 4):cky214. 73. doi: 10.1093/eurpub/cky214.273

43. AlHeresh R, Bryant W, Holm M. Community-based rehabilitation in Jordan: challenges to achieving occupational justice. Disabil Rehabil. 2013;35(21):1848-52. doi: 10.3109/09638288.2012.756944

44. Doocy S, Lyles E, Akhu-Zaheya L, Burton A, Weiss W. Health service utilization and access to medicines among Syrian refugee children in Jordan. Int J Health Plann Manag. 2016;31(1):97-112. doi: 10.1002/hpm.2336

45. Silove D, Steel Z, McGorry P, Drobny J. Problems Tamil asylum seekers encounter in accessing health and welfare services in Australia. Soc Sci Med. 1999;49(7):951-6. doi: 10.1016/ s0277-9536(99)00188-4

46. Rizkalla N, Segal SP. Well-being and posttraumatic growth among Syrian refugees in Jordan. J Trauma Stress. 2018; 31(2):213-22. doi:10.1002/jts.22281

47. Saab R, Jeha S, Khalifeh H, Zahreddine L, Bayram L, Merabi $Z$, et al. Displaced children with cancer in Lebanon: A sustained response to an unprecedented crisis. Cancer. 2018;124(7):1464-72. doi: 10.1002/cncr.31273 